\title{
Social Science and Life on the Move: Reflexive Considera- tions
}

\section{Charalambos Tsekeris}

\author{
Department of Psychology, Panteion University of Social and Political Sciences, Athens, Greece, \\ tsekeris@gmail.com
}

\begin{abstract}
Sociology and society are undoubtedly on the move. The present concise reflection seeks to comprehensively elaborate on both the social science and the social life within the contemporary dynamical world environment. In this context, brief elaborations are formulated on the complicated issue of technoscientific knowledge and its implications, as well as on a sustainable analytic framework for generating and developing further critical sociological and epistemological considerations about human agency and reflexivity.
\end{abstract}

Keywords: Knowledge, Reflexivity, Social Theory, Epistemology, Chaos

Acknowledgement: This reflection presents personal views of the author. It is a modified version of a paper presented at the 3rd Conference of the Hellenic Sociological Society (HSS), which was held November 3-5, 2011 in Athens, Greece.

Nowadays, the profound salience of technoscientific knowledge, biology/genetics, and the human body is not just important for philosophy, sociology and the human sciences; it is the fundamental basis on which significant life choices and life planning must be reflexively made by common people in their everyday social life.

Reflexively engaging with scientific expertise, genetic practices, and bodily knowledge is nowadays almost inevitable. Hence, the "received" or "conventional" notions of citizenship and public participation, personal and collective identity, social belonging and group membership, sexuality and well-being, health and cure, pathology or disease, and so on, are all being dynamically reinvented, especially in the light of new biotechnologies.

In addition, expert knowledge and the "universal objective facts", which common people hitherto accepted as matters of (unquestionable) scientific expertise and acted upon, are now perceived as the emergent outcomes of complex, uncertain, and heterogenous processes of social construction (or interested local interaction and negotiation), as well as of an immense variety of cognitivepolitical maneuvers within the wider field of academia.

Science and genetic knowledge, in particular, must now self-consciously articulate the very epistemic and social assumptions on which they desire to build - that is, an on-going, interactiveparticipatory, and self-renewing process. They should also re-discover and re-define their own place in a messy world which is in constant, dynamic and non-linear evolution.

This will further contribute to thinking about what it actually means to be human (or maybe posthuman), as well as about how to effectively cope with chaos/complexity (Tsekeris 2010) and our current techno-human condition, with the reflexive prospect of inventing a new global scientific citizenship and, perhaps, new communal forms of life.

We must finally revisit the untenable dichotomy between the natural and the social, or the natural and the artificial. We must then admit the hidden falsity of its universalism, reflexively embracing instead the idea of (why not?) a "New Enlightenment" based on sociological-philosophical imagination and the very principle "from local universalism to global contextualism" (Aboagora 2011).

This will help in pragmatically articulating actual problems of living, and critically suggesting possible practical solutions - possible policies, welfare programmes, political projects, philosophies of life, and so on. Most interestingly, real knowledge utopias are still possible because "their imaginary is infused with alternative criteria such as human dignity, collective justice, and the capacity to aspire (Arjun Appadurai) or because they include subaltern movements, while resisting the temptation to anchor their utopia in the quicksand of relativism. They will have to engage with existing hierarchies of knowledge production even as these are undergoing rapid transformation through the enormous global educational opportunities offered by the use of new technologies that open up knowledge monopolies, and through access to the co-production of knowledge" (Nowotny 2011) 
Two reflexive points are made here. First, the durable utopian dimension of the social and human sciences: As Giddens perceptively points out, "a little bit more utopian thinking might help too - well, why not? Politics in some ways has become deadly dull. We need more positive ideals in the world, but not empty ones - rather, they should be ideals that link to realistic possibilities of change" (Giddens 2006).

This wholly renewed style (and content) of thinking and argumentation must be definitively provisional, modest and weak (see Tsekeris and Koskinas 2010). In other words, social theory is "still alive, but not in the same way ... Perhaps 'theory' has not gone into decline, but rather has dispersed into, and helped construct, various social spaces that now seem to demand explication? Perhaps the only thing that has declined is a certain kind of theory - unified, overarching, certain of itself and its scientific ambitions?" (Reed and Alexander 2009, 25). ${ }^{1}$ Nevertheless, nothing could actually be "more important than rediscovering the passion for ideas" (Badiou 2010, 100).

Second, a reflexive resistance to the strong temptation to dangerously anchor knowledge utopias in the quicksand of relativism rather implies dialectically transcending both main approaches to the status of science and scientific knowledge:

On the one hand, the realist view of scientific knowledge in which "the theoretical entities that are characterized by a true theory do actually exist even though they might not be directly observable" (Richardson 2004, 18). So, the (allegedly) universally applicable scientific method can indeed offer an objective, impartial and absolute knowledge of the social and physical world - a real world "out there".

On the other hand, the idealist (or constructivist) view, according to which "knowledge is manufactured rather than discovered. The manufacturing process is inherently biased through our methods of production and is incapable of delivering objective value-free knowledge of external reality: objectivity becomes no more than a myth" (Richardson 2004, 18). Therefore, scientific knowledge is socially constructed and subjective in nature. As feminist "standpoint epistemologies" emphatically maintain, knowledge is actively performed from a specific social location, while the sovereign, totalizing view from "nowhere" (or "everywhere") is forever impossible. There is no universal, context-free, or "innocent" knowledge (Flax 1992).

Nowadays, the emergent co-operation between the natural and the social sciences open up the epistemologically healthy possibility for (many) third ways - beyond strong constructivism and naïve realism (see Strydom 2002; Delanty 1997; Fuchs 2008).

According to this synthetic or dialectical possibility, constructivism is no more burdened "by extreme claims suggesting a complete scientization of society on the one hand and on the other the reflexive individuation scenario of Giddens in which a new modernity based on individual choice linked to institutional reflexivity" (Delanty 2002, 283). In addition, realism increasingly becomes "unable to address the emergence of complex levels of reality that are products of the projects of social actors and of the evolution of cognitive structures which are also constitutive of social reality. Reality is always negotiated by social actors; it is never settled once and for all" (Delanty 2002, 283)

In this speedy, fluid and dynamic context, the "old", "received" or "conventional" analytical distinction "between nature and society and along with this the bifurcation of the sciences are no as longer important as they once were ... Knowledge has become a new field of political and of evolutionary/cognitive possibilities" (Delanty 2002, 284).

While the main theoretical advances in sociology nowadays no longer come from macrosociology but from the theory of action (namely, Luc Boltanski, Laurent Thévenot, Axel Honneth, Hans Joas, Margaret Archer, Jeffrey Alexander, Randall Collins, Bruno Latour, François Dubet, Nathalie Heinich, Bernard Lahire, Alain Caillé), knowledge also becomes more self-reflexive and capable of boosting the self-reflexivity of individuals, groups, and institutions. It will thus enable them "to integrate their experience, rendering knowledge more socially robust" (Nowotny 2010, 321).

In general, increased reflexivity may indeed be empowering, by allowing the social subject to critically oscillate "between the stability of habitual and positional structures, and the contingencies that surface within rapidly changing contemporary social realities. By synthesizing each of these causal powers within one theory of social action, it becomes possible to appreciate the complex

\footnotetext{
${ }^{1}$ For Reed and Alexander, what is actually needed is to reflexively envision and fashion the synthetic possibility of a cultural social science, which is "historically circumscribed, but it is also theoretically informed, empirically responsible, and epistemologically aware, and it searches for explanatory validity" (Reed and Alexander 2009, 36). Besides, sociology is a subject that strongly resists to any "formation as a discipline based around a fixed frame of reference or 'core'. In that sense, it is a discipline that has to be 'achieved', or continually re-invented in new circumstances" (Holmwood 2009, para 1.16).
} 
interplay between structure and agency" (Kemp 2010, 11). Of course, agency is understood here with Giddens as the capacity to act otherwise.

Researchers should then explore a fruitful plurality of methodologies and theories, strategies and questions, given that the social is strongly characterized by plasticity, fluidity, heterogeneity, and contingency. But the question of social ontology is irreducible. According to Margaret Archer, objective circumstances "as shaped by socio-cultural properties are real; we cannot make what we will of them with impunity. If the descriptions under which they are known are wildly divergent from reality, then reality will have revenge, because the strategy for pursuing a project will be defective" (Archer 2003, 139-140)

Within an empirically informed reflexive-realist ${ }^{2}$ framework, knowledge cannot and should not be erroneously confounded with the mere "recording and analysis of the 'pre-notions' (in Durkheim's sense) that social agents engage in the construction of social reality; it must also encompass the social conditions of the production of these pre-constructions and of the social agents who produce them" (Bourdieu 2003, 282). ${ }^{3}$

This "analytical dualism" is absolutely necessary for human agents' creative capacity to distance themselves cognitively from the objective social and cultural circumstances, in order to critically see and elaborate on them (meta-reflexivity). In other words, it is absolutely necessary for the sequential radical transformation of the passive "individual agent" (in a Bourdieusian sense) into a selfcritical social actor and role-taker.

Through the internal conversations (Archer 2003), we can possibly cultivate and enhance our meta-theoretical reflexivity, defined as a "stepping back from full engagement in cultural activity", or as a "form of ironic detachment: a disengagement from tribal custom and a heightened awareness of taken-for-granted assumptions" (Lynch 2000, 30). ${ }^{4}$

But this advanced kind of reflexivity, as Hans Herbert Koegler (1997a) rightly explains, should concurrently be both inward-looking (introverted) and outward-looking (extroverted), that is, a structural self-reflexivity (sharply distinguished from the instrumental and practical reflexivity of situated agents), resulting as the demiurgic combination of "individual self-reflexivity and socio-structural reflexivity, in so far as the constitution of oneself as an interpreting and evaluating agent is related to objective social contexts" (Koegler 1997a, 247, n. 3). ${ }^{5}$

Since the contemporary social world is so rapidly changing, we arguably need a chaos-relevant intellectual framework within which to attempt to make sense of it. In this framework, chaos is neither avoidable nor destructive; instead, it can be imaginatively theorised as a unique opportunity and capacity to think, co-act and change, as well as something we should responsibly accept, acknowledge, embrace, celebrate and live with (Tsekeris 2010).

Life is increasingly chaotic and chaos is indeed a very exciting thing. ${ }^{6}$ So, don't panic over chaos! Sociology should ultimately focus on the systematic study of uncertainty and unpredictability, rather than the infertile and unproductive attempt to overcome them. It should also empower the individuals to realise themselves (as parts of a self-organizing social network or system) in a more reflexive and self-determined way. In a critical vein, Christian Fuchs and Wolfgang Hofkirchner comprehensively conclude that a socially, ecologically and technologically sustainable way out of the current world-wide crisis could potentially be established by "the real self-organisation of the individuals that are confronted by the negative effects of global problems. The breakdown of the world system would mean the destruction of society's permanent re-creation-process. In order to maintain the re-creation of society, people who are excluded from the bottom-up-process, which establishes social information, and who are exploited in order to maintain the exclusive character of society would have to organise themselves, in the political sense of the term" (Fuchs and Hofkirchner 2005, 48)

\footnotetext{
${ }_{3}^{2}$ For the interesting and challenging notion of reflexive or circular realism, see Pels (2000).

${ }^{3}$ Of course, this should carefully refrain from any sort of "last-instance" objectivism and decisively move towards a rather never-ending reflexive dialectic between micro and macro, action and structure, transformation and reproduction, individuality and sociality (or individual and collective action), randomness and simplicity, contingency and directionality, emergence and social causation (Sawyer 2007), as well as towards a generalized critique of naïve/uncritical/unreflexive realism, reification and essentialism, at the level of both everyday world-making and professional scientific (sociological) analysis.

${ }^{4}$ For a superb analysis of the intriguing notion of "alienation as epistemological source", see the relevant sociological work of Hans Herbert Koegler (1997b).

${ }^{5}$ Obviously, this is heavily inspired by the Bourdieusian relational methodological notion of intellectual socioanalysis, or "self-socioanalysis" (see Bourdieu and Wacquant 1992).

${ }^{6}$ Chaos is the very structure of nature and like any structure is both enabling and constraining. This perfectly seems to generalize Giddens's (1984) "structuration theory".
} 


\section{References}

Aboagora. 2011. Accessed December 1, 2011. http://www.aboagora.fi

Archer, Margaret. 2003. Structure, Agency and Internal Conversation. Cambridge: Cambridge University Press.

Badiou, Alain. 2010. The Communist Hypothesis. London: VERSO.

Bourdieu, Pierre. 2003. Participant Objectivation. J. Roy. anthrop. Inst. 9: 281-294.

Bourdieu, Pierre, and Loic Wacquant. 1992. Invitation to a Reflexive Sociology. Chicago: University of Chicago Press.

Delanty, Gerard. 1997. Social Science: Beyond Constructivism and Realism. Buckingham: Open University Press.

Delanty, Gerard. 2002. Constructivism, Sociology and the New Genetics. New Genetics and Society 21 (3): 279-289.

Flax, Jane. 1992. The End of Innocence. In Feminists Theorise the Political, edited by Judith Butler and Joan Scott. London: Routledge.

Fuchs, Christian. 2008. Sociology, Dynamic Critical Realism, and Radical Constructivism. Constructivist Foundations 3 (2): 97-99.

Fuchs, Christian, and Wolfgang Hofkirchner. 2005. The Dialectic of Bottom-up and Top-down Emergence in Social Systems. tripleC - Cognition, Communication, Co-operation: Open Access Journal for a Global Sustainable Information Society 3 (2): 28-50. Accessed December 3, 2011. http://www.triple-c.at/index.php/tripleC/article/view/21/20

Giddens, Anthony. 1984. The Constitution of Society: Outline of the Theory of Structuration. Cambridge: Polity Press.

Giddens, Anthony. 2006. A Call to Arms. The Guardian, November 26.

Holmwood, John. 2009. The Challenge of Global Social Inquiry. Sociological Research Online 14 (4). Accessed December 1, 2011. http://www.socresonline.org.uk/14/4/13.html

Kemp, Christian. 2010. Building Bridges Between Structure and Agency: Exploring the Theoretical Potential for a Synthesis Between Habitus and Reflexivity. Essex Graduate Journal of Sociology 10: 4-12.

Koegler, Hans Herbert. 1997a. Reconceptualizing Reflexive Sociology. Social Epistemology 11 (2): 223-250.

Koegler, Hans Herbert. 1997b. Alienation as Epistemological Source: Reflexivity and Social Background After Mannheim and Bourdieu. Social Epistemology 11 (2): 141-64.

Lynch, Michael. 2000. Against Reflexivity as an Academic Virtue and Source of Privileged Knowledge. Theory, Culture \& Society 17 (3): 26-54.

Nowotny, Helga. 2010. Out of Science - Out of Sync? In World Social Science Report. Paris: UNESCO.

Nowotny, Helga. 2011. Producing Sociology in Today's Unequal World. Global Dialogue 2 (2). Accessed December 1 , 2011. http://www.isa-sociology.org/global-dialogue/2011/11/producing-sociology-in-today\%E2\%80\%99s-unequal-world

Pels, Dick. 2000. Reflexivity: One Step Up. Theory, Culture \& Society 17 (3): 1-25.

Reed, Isaac, and Jeffrey Alexander. 2009. Social Science as Reading and Performance: A Cultural-Sociological Understanding of Epistemology. European Journal of Social Theory 12 (1): 21-41.

Richardson, Kurt. 2004. The Problematization of Existence: Towards a Philosophy of Complexity. Nonlinear Dynamics, Psychology, and Life Sciences 8 (1): 17-40.

Sawyer, Keith. 2007. Social Emergence: Societies as Complex Systems. New York: Cambridge University Press.

Strydom, Piet. 2002. Risk, Environment and Society. Buckingham: Open University Press.

Tsekeris, Charalambos. 2010. Chaos and Unpredictability in Social Thought: General Considerations and Perspectives. Sociologija. Mintis ir veiksmas 27 (2): 34-47.

Tsekeris, Charalambos, and Konstantinos Koskinas. 2010. A "Weak" Reflection on Unpredictability and Social Theory. tripleC - Cognition, Communication, Co-operation: Open Access Journal for a Global Sustainable Information Society 8 (1): 36-42. Accessed December 3, 2011. http://www.triple-c.at/index.php/tripleC/article/viewArticle/183

\section{About the Author}

Charalambos Tsekeris

graduated with Distinction from Brunel University (West London, UK) and earned his doctoral degree in Reflexivity from Athens Panteion University (Department of Sociology). He is Member of the Hellenic Sociological Society (HSS) and Senior Researcher at the Lab of Virtual Reality, Internet Research \& E-Learning, Department of Psychology, Panteion University of Social and Political Sciences, Athens, Greece. His research interests involve human complex systems, psychosocial studies, epistemology, and social theory. email: tsekeris@gmail.com 